\title{
Odontologia legal - o papel do Odontolegista na identificação de cadáveres: uma revisão integrativa
}

\author{
Legal dentistry - the role of the Odontolegist in the identification of cadaveres: an integrating \\ review
}

Odontología legal: el papel del Dentista en la identificación de cadáveres: una revisión integradora

\author{
Anne Myrelle da Cruz Andrade \\ ORCID: https://orcid.org/0000-0003-2637-7271 \\ Universidade Tiradentes de Alagoas, Brasil \\ E-mail: annemyrelle@ hotmail.com \\ Júlia de Araújo Gomes \\ ORCID: https://orcid.org/0000-0003-1323-5071 \\ Universidade Tiradentes de Alagoas, Brasil \\ E-mail: juaraujogomes@hotmail.com \\ Laryssa Kelly Barbosa Ferro Oliveira \\ ORCID: https://orcid.org/0000-0001-6967-6461 \\ Universidade Tiradentes de Alagoas, Brasil \\ E-mail: laryssakellyferro@gmail.com \\ Luana Ranna Silva Santos \\ ORCID: https://orcid.org/0000-0002-2361-633X \\ Universidade Tiradentes de Alagoas, Brasil \\ E-mail: luanaranna2014@gmail.com \\ Savana Ranyella Correia da Silva \\ ORCID: https://orcid.org/0000-0002-2486-8408 \\ Universidade Tiradentes de Alagoas, Brasil \\ E-mail: savana1998@hotmail.com \\ Vanessa Silva de Moura \\ ORCID: https://orcid.org/0000-0002-3000-6230 \\ Universidade Tiradentes de Alagoas, Brasil \\ E-mail: vanessamoura37@gmail.com \\ Dayse Andrade Romão \\ ORCID: https://orcid.org/0000-0002-7884-1657 \\ Universidade Tiradentes de Alagoas, Brasil \\ E-mail: dayseromao@gmail.com
}

\begin{abstract}
Resumo
A Odontologia Legal, também conhecida como antropologia forense, é uma especialidade odontológica que aplica todos os conhecimentos na identificação de cadáveres através de seus registros e arcadas dentais. A revisão teve por objetivo analisar a literatura acerca da Odontologia legal relacionada à identificação de corpos humanos. Desenvolveu-se uma revisão integrativa da literatura nas bases de dados Lilacs, SciELO e PubMed em março de 2019, utilizando os descritores, "odontologia legal", "arco dental" e "cadáver" individualmente e em seguida o cruzamento com o operador booleano AND. Os critérios de inclusão para a seleção da amostra foram artigos publicados em português e inglês, disponíveis na íntegra, entre 2009 e 2020, que retratassem a temática. Foram encontrados 18 artigos e verificado que a grande demanda de identificação de cadáveres por parte civil e criminal, tornou os arcos dentários um valioso meio de identificação, essencialmente pela variedade de elementos a serem coletados. Portanto, há necessidade de se documentar todos os procedimentos e características da arcada dental do paciente feito pelo cirurgião-dentista, pois são estes dados que irão permitir um nível de sucesso maior na correta identificação do cadáver.
\end{abstract}

Palavras-chave: Odontologia legal; Arco dental; Cadáver.

\section{Abstract}

Legal Dentistry, also known as forensic anthropology, is a dental specialty that applies all knowledge in the identification of cadavers through their records and dental arches. The purpose of the review was to analyze the literature on legal dentistry related to the identification of human bodies. An integrative literature review was 
Research, Society and Development, v. 10, n. 2, e29210212465, 2021

(CC BY 4.0) | ISSN 2525-3409 | DOI: http://dx.doi.org/10.33448/rsd-v10i2.12465

developed in the Lilacs, SciELO and PubMed databases in March 2019, using the descriptors, "legal dentistry", "dental arch" and "cadaver" individually and then the crossing with the Boolean operator AND. The inclusion criteria for the selection of the sample were articles published in Portuguese and English, available in full, between 2009 and 2020, that portrayed the theme. 18 articles were found and it was verified that the great demand for the identification of corpses by civil and criminal parties, makes dental arches as an important means of identification, mainly due to the diversity of elements to be collected. Therefore, there is a need to document all the procedures and characteristics of the patient's dental arch made by the dentist, as these are the data that will allow a greater level of success in the correct identification of the corpse.

Keywords: Forensic dentistry; Dental arch; Cadaver.

\section{Resumen}

La Odontología Legal, también conocida como antropología forense, es una especialidad odontológica que aplica todos los conocimientos en la identificación de cadáveres a través de sus registros y arcos dentales. El propósito de la revisión fue analizar la literatura sobre odontología legal relacionada con la identificación de cuerpos humanos. Se desarrolló una revisión integradora de la literatura en las bases de datos Lilacs, SciELO y PubMed en marzo de 2019, utilizando los descriptores, "odontología legal", "arco dental" y "cadáver" individualmente y luego el cruce con el operador booleano AND. Los criterios de inclusión para la selección de la muestra fueron artículos publicados en portugués e inglés, disponibles íntegramente, entre 2009 y 2020, que retrataran la temática. Se encontraron 18 artículos y se constató que la gran demanda de identificación de cadáveres por parte de la parte civil y penal, hace que los arcos dentarios sean un importante medio de identificación, principalmente por la diversidad de elementos a recolectar. Por tanto, existe la necesidad de documentar todos los procedimientos y características de la arcada dental del paciente realizados por el odontólogo, ya que estos son los datos que permitirán un mayor nivel de éxito en la correcta identificación del cadáver.

Palabras clave: Odontología legal; Arco dental; Cadaver.

\section{Introdução}

O aumento da violência urbana no cenário mundial, envolvendo principalmente traumas dentomaxilofaciais, evidencia o papel da odontologia legal, pois esta contribui para a justiça devido à importância do conhecimento técnico e cientifico (Valente et al., 2018). A Odontologia Legal, também conhecida como antropologia forense, é uma especialidade odontológica que aplica todos os conhecimentos na identificação de cadáveres através de seus registros e arcadas dentais (Junior; Moura, 2014).

Os odontolegistas são profissionais capacitados para realizar perícias, que podem ser realizadas em foro civil, criminal, trabalhista e em sede administrativa, segundo a Lei $\mathrm{n}^{\circ}$ 5.081/66 (Jacometti et al., 2017). A procura por formação nessa área vem apresentando um aumento significativo, sendo assim, fica evidente que é um tema amplo e atual, necessário de ser estudado (Junior; Moura, 2014).

Sendo o Perito Oficial capacitado legalmente para a realização de perícias, cabe a ele a tarefa de identificar, transcrever e discutir as evidências oriundas da violência física em cabeça e pescoço, especialmente quanto às lesões corporais gravíssimas qualificadas por deformidades permanentes (Valente et al., 2018). A perícia odontológica é de fundamental importância no âmbito forense, pois através dela podemos realizar a identificação de registros ante mortem de pessoas desaparecidas, em casos de acidentes em desastres em massa e corpos em estado de decomposição (Barbosa et al., 2010; Castro et al., 2018).

O processo de identificação humana é iniciado às vezes antes mesmo de se saber a causa da morte, para que as vítimas possam ter seus direitos garantidos e preservados. Esse processo se dá através de técnicas forenses, métodos e recursos que contribuem para a identificação inicial como, o sexo, idade, a cor de pele até chegar à identidade das vítimas (Carvalho et al., 2009). Alguns destes recursos utilizados são os exames clínicos, fichas odontológicas fornecidas pelos cirurgiões-dentistas das vítimas, exames de imagens radiográficas e modelos de gesso ante mortem para comparação com os arcos dentais do cadáver (Barbosa et al., 2010). 
Research, Society and Development, v. 10, n. 2, e29210212465, 2021

(CC BY 4.0) | ISSN 2525-3409 | DOI: http://dx.doi.org/10.33448/rsd-v10i2.12465

Desta forma o objetivo deste estudo foi analisar a literatura acerca da Odontologia legal relacionada à identificação de corpos humanos. Ressaltando o papel do odontolegista para identificação dos corpos através de exames radiográficos e do DNA contido nos dentes. E viabilizando a solução de casos judiciais, através da investigação a identidade de corpos encontrados.

\section{Material e Métodos}

O presente artigo trata-se de um estudo do tipo revisão integrativa da literatura com caráter qualitativo (Pereira et al., 2018), que se constitui em um tipo de pesquisa mais ampla permitindo a inclusão de estudos experimentais e não experimentais, literatura teórica e empírica para se obter um profundo conhecimento sobre o tema abordado.

Sua elaboração foi baseada nas etapas descritas por Mendes et al. (2008): pergunta norteadora da pesquisa, busca na literatura, categorização dos estudos, avaliação dos estudos, interpretação dos resultados e síntese do conhecimento. A questão norteadora utilizada para guiar a pesquisa foi: “Como a odontologia legal pode contribuir para a identificação de cadáveres?”.

Para realização do artigo foi realizado um levantamento bibliográfico dos últimos onze anos nas bases de dados Literatura Latino-Americana e do Caribe em Ciências da Saúde (LiLACS), Scientific Electronic Library Online (SCIELO) e US National Library of Medicine (Pubmed). Para busca dos artigos foram utilizados como descritores: "odontologia legal", “arco dental” e "cadáver". O levantamento bibliográfico foi realizado entre março de 2019 e outubro de 2020. Inicialmente, a busca pelos descritores foi feita individualmente e em seguida foram realizados os cruzamentos utilizando o operador booleano AND. Os critérios de inclusão para a seleção da amostra foram artigos publicados em português e inglês, disponíveis na íntegra, entre 2009 e 2020, que retratam a temática em estudo. Já os critérios de exclusão foram artigos publicados antes de 2009, em idiomas que não fossem inglês e português, teses, trabalhos de conclusão de curso e dissertações.

\section{Resultados}

No presente estudo, as bases de dados nacionais Lilacs e SciELO apresentaram maiores números de resultados em acordo com os critérios de inclusão adotados. A base de dados Lilacs resultou em mais artigos relevantes após a leitura do resumo seguida pela SciELO. Na base de dados intenacional Pubmed foram selecionados apenas dois artigos relevantes ao levantamento bibliográfico por meio da palavra chave forensic dentistry. Além disso, é importante mencionar que, em todas as bases de dados utilizadas a busca com os termos isolados obteve-se maior retorno de artigos do que o uso combinado de dois e três termos.

O quadro a seguir expõe os artigos selecionados nas bases de dados. 
Research, Society and Development, v. 10, n. 2, e29210212465, 2021

(CC BY 4.0) | ISSN 2525-3409 | DOI: http://dx.doi.org/10.33448/rsd-v10i2.12465

Quadro 1. Artigos incluídos na Revisão integrativa.

\begin{tabular}{|c|c|c|c|c|}
\hline Título & Autores & Ano & Delineamento & Desfecho \\
\hline $\begin{array}{l}\text { A utilização de imagens na } \\
\text { identificação humana em } \\
\text { odontologia legal. }\end{array}$ & $\begin{array}{l}\text { Carvalho, S. P. M., et } \\
\text { al. }\end{array}$ & 2009 & Revisão sistemática & $\begin{array}{l}\text { As radiografias e tomografias ante-mortem e post-mortem tornaram-se ferramentas } \\
\text { de grande importância nos processos de identificação humana em odontologia } \\
\text { legal. }\end{array}$ \\
\hline $\begin{array}{l}\text { A importância do prontuário } \\
\text { odontológico nas perícias de } \\
\text { identificação humana. }\end{array}$ & Paranhos, L. R., et al. & 2009 & Relato de caso & $\begin{array}{l}\text { O odontolegista irá avaliar os prontuários odontológicos fornecidos pelos } \\
\text { cirurgiões-dentistas de vítimas que tiveram seus corpos carbonizados ou } \\
\text { desfigurados. }\end{array}$ \\
\hline $\begin{array}{l}\text { Utilização de documentação } \\
\text { ortodôntica na identificação } \\
\text { humana. }\end{array}$ & Silva, R. F. da, et al. & 2011 & Relato de caso pericial & $\begin{array}{l}\text { Informações como arcada dentária, fotografias e moldes de gesso servem de auxílio } \\
\text { para a identificação de um cadáver que tenha sido carbonizado. }\end{array}$ \\
\hline $\begin{array}{l}\text { Identificação humana por meio } \\
\text { do estudo de imagens } \\
\text { radiográficas odontológicas: } \\
\text { relato de caso. }\end{array}$ & Scoralick, R. A., et al. & 2013 & Relato de caso & $\begin{array}{l}\text { O exame radiográfico é um dos documentos que compõe o prontuário } \\
\text { odontológico, que quando produzidos e arquivados corretamente podem servir para } \\
\text { fins de identificação humana. }\end{array}$ \\
\hline $\begin{array}{l}\text { O papel do Odontolegista nas } \\
\text { perícias criminais. }\end{array}$ & $\begin{array}{l}\text { Coutinho, C. G. V., et } \\
\text { al. }\end{array}$ & 2013 & Revisão de literatura & $\begin{array}{l}\text { O cirurgião-dentista pode atuar em análises, perícias criminais, tanatologia forense, } \\
\text { avaliação e identificação humana. }\end{array}$ \\
\hline $\begin{array}{l}\text { A importância dos arcos } \\
\text { dentários na identificação } \\
\text { humana. }\end{array}$ & $\begin{array}{l}\text { Junior, E. F.; } \\
\text { MOURA, L. C. L. de. }\end{array}$ & 2014 & Revisão de literatura & $\begin{array}{l}\text { Os arcos dentários vêm se tornando um importante meio de identificação, } \\
\text { principalmente pela diversidade de elementos a serem coletados. }\end{array}$ \\
\hline $\begin{array}{l}\text { Regulamentação legal da } \\
\text { perícia oficial odontolegal nos } \\
\text { estados brasileiros. }\end{array}$ & Costa, P. B., et al & 2016 & Estudo transversal & $\begin{array}{l}\text { O odontolegista tem direito de atuar em área criminal como nas áreas cível, } \\
\text { trabalhista e administrativa. }\end{array}$ \\
\hline $\begin{array}{l}\text { A história da odontologia legal } \\
\text { no Brasil. Parte 1: origem } \\
\text { enquanto técnica e ciência. }\end{array}$ & Silva, R. F., et al. & 2017 & Revisão de literatura & $\begin{array}{l}\text { A Odontologia legal vai muito além e relaciona questões como a ética na } \\
\text { odontologia, legislação, perícia e assistência técnica em áreas judiciais e } \\
\text { administrativas. }\end{array}$ \\
\hline $\begin{array}{l}\text { A história da odontologia legal } \\
\text { no Brasil. Parte 2: origem } \\
\text { enquanto disciplina e } \\
\text { especialidade. }\end{array}$ & Silva, R. F., et al. & 2017 & Revisão de literatura & $\begin{array}{l}\text { À medida que a Odontologia Legal ganha espaço enquanto ciência e técnica, a } \\
\text { justiça investe em ferramentas periciais para a elucidação de casos com significante } \\
\text { impacto social. }\end{array}$ \\
\hline
\end{tabular}


Research, Society and Development, v. 10, n. 2, e29210212465, 2021

(CC BY 4.0) | ISSN 2525-3409 | DOI: http://dx.doi.org/10.33448/rsd-v10i2.12465

\begin{tabular}{|c|c|c|c|c|}
\hline $\begin{array}{l}\text { Atuação do cirurgião-dentista } \\
\text { no instituto geral de perícias de } \\
\text { Joinville, SC. }\end{array}$ & $\begin{array}{l}\text { Miguel, L. C. M., et } \\
\text { al. }\end{array}$ & 2017 & Estudo quantitativo & $\begin{array}{l}\text { O odontolegista pode realizar a exames de corpo delito, exames de DNA, exames } \\
\text { tanatológicos, antropológicos, entre outros. }\end{array}$ \\
\hline $\begin{array}{l}\text { Perícias trabalhistas em } \\
\text { odontologia legal: } \\
\text { credenciamento e honorários do } \\
\text { perito judicial no Brasil. }\end{array}$ & Jacometti, V., et al. & 2017 & Estudo transversal & $\begin{array}{l}\text { Em processos judiciais é importante a presença de um perito, pois o esclarecimento } \\
\text { em casos é indispensável para uma decisão devidamente fundamentada. }\end{array}$ \\
\hline $\begin{array}{l}\text { Análise das sentenças judiciais } \\
\text { envolvendo deformidades } \\
\text { permanentes em cabeça e } \\
\text { pescoço na jurisprudência dos } \\
\text { tribunais da região sul do } \\
\text { Brasil. }\end{array}$ & $\begin{array}{l}\text { Valente, R. P. A., et } \\
\text { al. }\end{array}$ & 2018 & Relato de caso & $\begin{array}{l}\text { A documentação realizada pelo cirurgião dentista pode caracterizar uma lesão } \\
\text { corporal grave ao paciente resultando em deformidades permanentes em cabeça e } \\
\text { pescoço. }\end{array}$ \\
\hline $\begin{array}{l}\text { Análise odontológica de } \\
\text { detalhes anatômicos incisais e } \\
\text { oclusais, em especial "flor de } \\
\text { lis", para identificação forense - } \\
\text { relato de caso. }\end{array}$ & $\begin{array}{l}\text { Castro, A. G. B. de., } \\
\text { et al. }\end{array}$ & 2018 & Relato de caso & $\begin{array}{l}\text { A identificação humana é feita pela análise das particularidades de cada indivíduo, } \\
\text { inclusive odontológicas, como o arco dental. }\end{array}$ \\
\hline $\begin{array}{l}\text { Avaliação penal de lesões } \\
\text { dentais por peritos } \\
\text { odontolegistas de Instituto } \\
\text { Médico Legal - Brasil. }\end{array}$ & Queiroz, C. S., et al. & 2018 & Estudo de caso & $\begin{array}{l}\text { A avaliação por peritos odontolegistas registra laudos baseados em uma } \\
\text { classificação penal de lesões bucomaxilofaciais, onde as mais frequentes foram } \\
\text { pontuadas e analisadas. }\end{array}$ \\
\hline $\begin{array}{l}\text { Digitalização em odontologia } \\
\text { forense: uma mudança de } \\
\text { paradigma nas investigações } \\
\text { forenses. }\end{array}$ & Nagi, R., et al. & 2019 & Revisão de literatura & $\begin{array}{l}\text { A modernização da metodologia forense tradicional proporcionou grandes avanços } \\
\text { em relação à eficácia e fidelidade de provas, bem como na redução de custos e } \\
\text { aplicação em maiores áreas. }\end{array}$ \\
\hline Odontologia Forense & Mohammed, F., et al. & 2020 & Revisão de literatura & $\begin{array}{l}\text { A odontologia forense é uma prática crucial para variáveis condições físicas e } \\
\text { ambientais, provocadas ou não, as quais o corpo foi submetido. }\end{array}$ \\
\hline
\end{tabular}

Fonte: Autores (2020) 
Verifica-se no quadro acima que os artigos foram publicados entre 2009 a 2020, nos quais 16 foram selecionados e organizados por meio de fichamento, em ordem numérica crescente, tendo um (1) artigo de revisão sistemática, seis (6) artigo de relato de caso, sendo um pericial, seis (6) artigos de revisão de literatura, dois (2) artigos de estudos transversais e um (1) artigo de estudo quantitativo, proporcionando assim a aproximação inicial com o tema. Em seguida, os artigos foram submetidos a leitura na íntegra, tendo como finalidade proporcionar uma melhor busca dos dados apresentados pelos artigos, além de visar uma realização de análise interpretativa.

\section{Discussão}

Ao passo que a violência urbana aumenta anualmente no cenário mundial, observa-se o grande número de demandas judiciais que envolvem danos estéticos decorrentes de traumas dentomaxilofaciais. Dessa forma, em paralelo aos eventos relacionados ao Direito que permeiam as lesões corporais, tem-se na Odontologia Legal uma especialidade Odontológica estruturada para respaldar os interesses da Justiça por meio da contribuição com conhecimento técnico e científico (Valente et al., 2018). A avaliação por peritos odontolegistas registra laudos baseados em uma classificação penal de lesões bucomaxilofaciais (Queiroz et al., 2012).

É visto que a área de atuação da Odontologia Legal, ao contrário do que se pode esperar, não está restrita à parte técnica aplicada aos exames cadavéricos para identificação humana ou nos traumas decorrentes de lesões corporais por agressão, rotina esta executada nos serviços de Perícia Oficial, mais especificamente nos Institutos Médico-Legais. A Odontologia Legal vai mais além e abordam questões relacionadas com a ética odontológica, legislação aplicada ao exercício da Odontologia, perícia e assistência técnica em áreas administrativas e judiciais (civil, criminal, trabalhista), dentre outras (Silva et al., 2017).

A perícia é compreendida como um ato realizado que visa um esclarecimento científico e técnico para a justiça ou autoridades competentes. Logo, as perícias são ações atribuídas a profissionais experientes e capacitados em determinada área. E, nesse sentido, a Lei $n^{\circ} 5.081 / 66$, responsável por regulamentar a profissão odontológica no Brasil traz em seu artigo $6^{\circ}$, inciso IV o seguinte: "Compete ao cirurgião dentista: proceder à perícia odontolegal em foro civil, criminal, trabalhista e em sede administrativa" (Jacometti et al., 2017).

É de responsabilidade do perito oficial cirurgião-dentista emitir laudo conclusivo no que se refere à capacidade ou incapacidade laboral e compete à junta odontológica oficial, quando considerar necessário, requisitar pareceres de cirurgiõesdentistas especialistas, ou profissionais de outras áreas para elucidação de diagnósticos, expor opinião em assuntos de suas competências ou para documentar laudos odontopericiais (Coutinho et al., 2013).

No ambiente trabalhista as perícias odontológicas se dividem em: perícias no campo da saúde do trabalhador e perícias trabalhistas judiciais. A primeira o cirurgião-dentista, realiza inspeções e exames nos trabalhadores, aliando a prevenção e promoção de saúde no ambiente de trabalho. O segundo se trata das perícias realizadas por perito nomeado pelo Juiz, em ações trabalhistas e, em sua maioria, contemplando os acidentes ou doenças decorrentes da atividade laboral que causam danos ao trabalhador que exige, por meios legais, a reparação deste (Jacometti et al. 2017).

A inexistência do odontolegista no IML pode resultar em inadequado reconhecimento de lesões bucais, sendo prejudicial no relato das lesões em âmbito civil e penal. $\mathrm{Na}$ análise de corpos carbonizados, quando há o acesso ao prontuário odontológico do desaparecido, sua identificação é perfeitamente viável pela comparação dos odontogramas e outros registros, bem como fotografias e radiografias (Miguel et al., 2017).

Devido essa grande demanda de identificação de cadáveres por parte civil e criminal, os arcos dentários estão se tornando um valioso meio de identificação, essencialmente pela variedade de informações a serem reunidas, porém esse 
processo pode ser falho, exigindo métodos mais específicos para determinar a identidade de um indivíduo (Castro et al., 2018). Em casos em que o indivíduo não foi identificado por outros métodos, é feito a reconstrução facial, para isso, é avaliada a espessura do tecido mole facial em determinadas populações para que possam facilitar de um indivíduo futuramente (Silva et al., 2011; Junior, Moura, 2014).

Portanto, o cirurgião-dentista possui extrema importância no corpo dos órgãos oficiais de perícia por se tratarem dos únicos e verdadeiros conhecedores da área. Em âmbito criminal, estão vinculados a Institutos de Medicina Legal (IML), Institutos de Criminalística (IC) ou Institutos Geral de Perícias (IGP). Podem desenvolver identificação no vivo, em cadáver, perícias antropológicas em crânio, perícias de lesões corporais e manchas, determinação da idade, determinação de embriaguez alcoólica e outros exames (Lima et al., 2016). Porém, esta especialidade está consolidada como ciência em sua totalidade, reconhecida pela sua importância e valor forense e com centros de formação profissional em todo o território nacional, por fruto de uma incansável dedicação de grandes professores, peritos e pesquisadores desde o século XIX até a atualidade (Silva et al., 2017).

Exames de imagens, como radiografias comuns, digitalizadas e tomografias computadorizadas apresentam grande importância nos processos de identificação humana em odontologia legal, incluindo a determinação do gênero, do grupo étnico e, principalmente, da idade. Quando o corpo precisa de identificação, podem ser realizadas radiografias e posteriormente compará-las com alguma radiografia do corpo quando ainda estava com vida (Carvalho et al., 2009). Cadáveres em estado de putreficação, carbonizados, desfigurados ou esqueletizados que não possibilitem a sua fácil identificação são levados para o estudo de identificação no qual o Odontolegista irá avaliar os prontuários odontológicos fornecidos pelos cirurgiões-dentistas das vítimas, estes, quando produzidos e arquivados corretamente podem servir para fins de identificação humana (Paranhos et al., 2009; Scoralick et al., 2013).

Os dentes, em especial, os molares são fontes importantes de DNA, extraído a partir da polpa dentária. Vestígio de grande importância nos casos onde o material encontra-se muito deteriorado, pois é possível encontrar DNA mitocondrial de pequenas porções de osso (Sousa et al., 2013). Além disso, os métodos forenses tradicionais foram modernizados pela perícia digital que trouxe custos reduzidos e resultados eficazes por apresentarem menor chance de erro, utilizada principalmente em casos de desastres, terremotos e ataques terroristas abrangendo explosivos químicos, radiológicos ou nucleares (Nagi et al., 2019; Mohammed et al., 2020).

Nesse sentido, a Odontologia Legal, conforme conceituada por Luiz Lustosa da Silva (1924), criador desta especialidade no Brasil, é a arte de "aplicar os conhecimentos odontológicos à ação dos poderes públicos administrativo, judiciário e legislativo" 1 , ou seja, é a especialidade odontológica que disponibiliza todos os conhecimentos odontológicos a serviço do Direito e da Justiça, conceito este já consagrado no âmbito odontológico e nas Ciências Forenses (Silva et al., 2017).

\section{Conclusão}

A identificação pericial possui junção de inúmeras áreas profissionais, dentre elas, a área da odontologia legal. Dessa forma, o cirurgião-dentista por meio da especialidade de antropologia forense possui capacidade de atuar como perito e permitir maior precisão nos laudos dos cadáveres em questão.

Contudo, nota-se a necessidade que trabalhos futuros abordem a importância que o cirurgião-dentista tem em arquivar os prontuários, as radiografias e os modelos em gesso dos pacientes, além de anotar todas as informações, pois estas podem servir para a identificação positiva de vítimas e permitir um nível de sucesso maior na correta identificação do cadáver. 
Research, Society and Development, v. 10, n. 2, e29210212465, 2021

(CC BY 4.0) | ISSN 2525-3409 | DOI: http://dx.doi.org/10.33448/rsd-v10i2.12465

\section{Referências}

Carvalho, S. P. M., Silva, R. H. A., Lopes J. C., \& Peres, A. S. (2009). A utilização de imagens na identificação humana em odontologia legal. Revista Radiologia Brasileira, 42(2), 125-130. https://doi.org/10.1590/S0100-39842009000200012

Castro, A. G. B., Galvão, M. F., Melo, C. H. O., Silva, A. E., \& Trindade, A. F. (2018). Análise odontológica de detalhes anatômicos incisais, em especial "flor de lis", para identificação forense - relato de caso. Revista Brasileira Odontologia Legal - RBOL, 5(2), 85-93. https://doi.org/10.21117/rbol.v5i2.204

Coutinho, C., Ferreira, C., Queiroz, L., Gomes, L., \& Silva, U. (2014). O papel do Odontolegista nas perícias criminais. Revista Da Faculdade De Odontologia - UPF, 18(2). https://doi.org/10.5335/rfo.v18i2.3399

Jacometti, V., Buzelli, I. M. L., \& Silva, R. H. A.. (2017) Perícias trabalhistas em odontologia legal: credenciamento e honorários do perito judicial no Brasil. Revista Brasileira Odontologia Legal - RBOL, 4(3), 2-12. https://doi.org/10.21117/rbol.v4i3.112

Enio, J. \& Moura, L. (2014). A importância dos arcos dentários na identificação humana. Revista Brasileira de Odontologia, 71(1), 22-27. http://dx.doi.org/10.18363/rbo.v71n1.p.22

Costa, P. B., Silva, R. F. da, \& Silva, R. H. A. da. (2016). Associação Brasileira de Ética e Odontologia Legal (ABOL). Regulamentação legal da perícia oficial odontolegal nos estados brasileiros. Revista Brasileira de Odontologia Legal (RBOL), 3 (2), 123-130. https://doi.org/10.21117/rbol.v4i1.85

Miguel, L. C. M., Perícolo, S., Oliveira, S., Gaedke, A., Molina, C. G., \& Michels, B. (2017). Atuação do cirurgião-dentista no Instituto Geral de Perícias de Joinville, SC. Revista ABENO, 17(2). https://doi.org/10.30979/rev.abeno.v17i2.357

Mohammed, F., Fairozekhan, A. T., Bhat, S., \& Menezes, R. G. (2020). Forensic Odontology. Treasure Island, FL: StatPearls Publishing. https://www.ncbi.nlm.nih.gov/books/NBK540984/

Nagi, R., Aravinda, K., Rakesh, N., Jain, S., Kaur, N., \& Mann, A. K. (2019). Digitization in forensic odontology: A paradigm shift in forensic investigations. Journal of forensic dental sciences, 11(1), 5-10. https://doi.org/10.4103/jfo.jfds_55_19

Paranhos, L. R., Caldas, J. C. F., Iwashita, A, R., Scanavini, M. A. \& Paschini, R. C. (2009). A importância do prontuário odontológico nas perícias de identificação humana. Revista da Faculdade de Odontologia - UPF, 14(1). https://doi.org/10.5335/rfo.v14i1.689

Pereira, A. S., Shitsuka, D. M., Parreira, F. J., \& Shitsuka, R. (2018). Metodologia da pesquisa científica (1. ed.). Santa Maria, RS: UFSM, NTE. https://repositorio.ufsm.br/bitstream/handle/1/15824/Lic_Computacao_Metodologia-Pesquisa-Cientifica.pdf?sequence=1 .

Queiroz, C., Galo, R., Flores, M., Ortiz, A., \& Alves da Silva, R. (2018). Evaluación penal de lesiones dentales por expertos odontolegistas de Instituto Médico Legal - Brasil. Revista Cubana Estomatol, 55(1), 2-8. Recuperado de http://www.revestomatologia.sld.cu/index.php/est/article/view/1196/402

Scoralick, R. A., Barbieri, A. A., Moraes, Z. M., Francesquini J. L., Daruge J. E. \& Naressi, S. C. M. (2013). Identificação humana por meio do estudo de imagens radiográficas odontológicas: relato de caso. Revista de Odontologia da UNESP, 42(1), 67-71. https://doi.org/10.1590/S1807-25772013000100012

Silva, R. F. da., Chaves, P., Paranhos, L. R., Lenza, M. A., \& Daruge J., E. (2011). Utilização de documentação ortodôntica na identificação humana. Dental Press Journal of Orthodontics, 16(2), 52-57. https://doi.org/10.1590/S2176-94512011000200007

Silva, R. \& Franco, A. \& Oliveira, R., Júnior, E. \& Alves, da S. R. H. (2017). A história da odontologia legal no brasil. Parte 1: origem enquanto técnica e ciência. Revista Brasileira de Odontologia Legal, 4(3), 87-103. https://doi.org/10.21117/rbol.v4i2.139

Silva, R., Franco, A., Matoso, R., Alves da S. R. H. (2017). A história da odontologia legal no brasil - parte 2: origem enquanto disciplina e especialidade. Revista Brasileira de Odontologia Legal, 4(3), 67-88. https://doi.org/10.21117/rbol.v4i3.149

Valente, R. P. A., Franco., Silva, R. F. \& França, B. H. S. (2018). Análise das sentenças judiciais envolvendo deformidades permanentes em cabeça e pescoço na jurisprudência dos tribunais da região sul do brasil. Revista Brasileira de Odontologia Legal, 5(2), 39-48. https://doi.org/10.21117/rbol.v5i2.178 